Proceedings

\title{
Nature-Based Solutions (NBSs) Application for Hydro-Environment Enhancement. A Case Study of the Isar River (DE) ${ }^{\dagger}$
}

\author{
Francesco Pugliese 1,* , Gerardo Caroppi ${ }^{1}$, Aude Zingraff-Hamed ${ }^{2}$, Gerd Lupp ${ }^{2}$ \\ and Maurizio Giugni ${ }^{1}$ \\ 1 Department of Civil, Architectural and Environmental Engineering, University of Naples Federico II, \\ 80125 Naples, Italy; gerardo.caroppi@unina.it (G.C.); maurizio.giugni@unina.it (M.G.) \\ 2 TUM School of Life Sciences - Weihenstephan Campus, Technical University of Munich, \\ D-85354 Freising, Germany; aude.zingraff-hamed@tum.de (A.Z.-H.); gerd.lupp@tum.de (G.L.) \\ * Correspondence: francesco.pugliese2@unina.it; Tel.: +39-081-7683453 \\ + Presented at the 4th EWaS International Conference: Valuing the Water, Carbon, Ecological Footprints of \\ Human Activities, Online, 24-27 June 2020.
}

Published: 26 August 2020

\begin{abstract}
In mountain areas, natural hazards, e.g., flooding, snow avalanches, droughts, and landslides are triggered by climate change, anthropization, and economic development. Nature-Based Solutions (NBSs) are attracting increasing interest as they are able to couple technical solutions against natural hazards with ecological and socio-economic resilience. On this matter, the four-year H2020 Innovation Action "PHUSICOS-According to Nature" (Grant Agreement nr. 776681) project aims to assess the effectiveness of NBSs and hybrid solutions to hinder hydro-meteorological events in rural and mountainous areas in Europe. Among the ongoing activities within the project, a multi-criteria tool was implemented to assess the effectiveness of NBSs measures from the technical, environmental, and socio-economic perspectives. In this work, the preliminary application of the assessment tool to the Isar River (DE) PHUSICOS concept case is discussed, with reference to an ex-post analysis of the flood risk management plan, comparing the performances of the implemented NBS project scenario against a potential grey solution.
\end{abstract}

Keywords: PHUSICOS; multi-criteria assessment; Nature-Based Solutions (NBSs); flood risk mitigation; Isar river restoration

\section{Introduction}

Extreme hydro-meteorological events, i.e., floods, droughts, storm surges, landslides, and snow avalanches are significantly intensifying all over the world, including Europe [1]. To promote the Disaster Risk Reduction (DRR), in contrast with the expensive design and management costs of traditional engineered Grey Solutions (GSs), the application of Nature-Based Solutions (NBSs) and Hybrid Solutions (HSs) in both urban and rural contexts is of increasing attractiveness for technicians, policy makers, and scientists [2,3]. Indeed, the European Union (EU) Research and Innovation (R\&I) agenda is activating several initiatives, aimed at promoting ecosystem-based approaches to hinder DRR and the effects of Climate Change (CC) [4].

The water management and planning practices took a decisive turn in the late 20th century [5]. A more responsible use of the resource and strategic planning in compliance with high environmental quality standards are at the top of the European political, research, and action agendas [6]. The concept of NBSs appeared in the continuity with the development of green infrastructures, bluegreen corridors, and ecological oriented planning trends. NBSs are intended as living solutions 
inspired by nature, resulting in cost-effective, adaptable, and resource-efficient, able to provide not only benefits in terms of DRR but also from the socio-economic and environmental viewpoints [7].

In this context, the European Commission (EC) activated the H2020-SC5-08-2017-Innovation Action call for financing projects working on the promoting and application of NBSs at large-scale demonstrator sites for hydro-meteorological risk reduction. Among the financed projects, "PHUSICOS-According to Nature" (https://phusicos.eu/; Grant Agreement nr. 776681) is a fouryear project (May 2018-April 2022) devoted to assessing the technical, socio-economic, and environmental effectiveness of NBSs or HSs for limiting the risk of extreme weather events in rural mountainous sites. These areas, as a consequence of the peculiar hydro-meteorological and site properties, are affected by multi-hazard events and are generally affected by specific socio-economic conditions, in many cases marked out by the decrease in both population and economic activities [8]. To bridge the current knowledge gap on NBSs and their effectiveness in reducing risk, in the frame of the PHUSICOS project, three large-scale demonstrator cases (Serchio River Basin in Italy, the Pyrenees in Spain, France, and Andorra, and the Valley of Gudbrandsdalen in Norway) were selected. In addition, two concept cases (the Kaunertal Valley in Austria and the Isar River Basin in Germany) were defined to test specific applications and for learning from already implemented NBSs measures. The project includes 15 partners from 7 EU Countries (Norway, Germany, Austria, Italy, France, Spain, and Andorra) with different expertise, useful for analyzing the NBSs application with an overall multi-disciplinary approach. Among the ongoing activities, the activation of Living Labs (LLs) at the demonstrator and concept cases is allowing the engagement of a different range of Stakeholders, promoting a participative approach in implementing the NBS practices. Thus, NBSs and HSs promotion in rural mountain areas are intended as sustainable and effective approaches for coupling the DRR with multi-level co-benefits.

Among the activities implemented so far in the frame of the PHUSICOS project, a Multi-Criteria Decision Analysis (MCDA) [9-11] was performed to assess the performances of NBSs and HSs at specific demonstrator sites and concept cases of the project, according to a structured scheme able to effectively involve the stakeholders in the decision process. Namely, a comprehensive multi-level framework tool was implemented and tested [12] for the multi-disciplinary assessment of the NBS performances in the design and/or monitoring stages. The tool requires the estimation of a set of Key Performance Indicators (KPIs) belonging to technical, socio-economic, and environmental ambits, representing a useful tool for the comparative analysis of alternative design scenarios, with respect to the status quo (Baseline Scenario, BS).

In this work, the results of the application of the proposed tool to the Isar River (DE) concept case are described. Specifically, the preliminary assessment of benefits deriving from the river flood risk management plan was carried out by comparing the performance of the implemented project scenario with a virtual grey solution, against the pre-intervention one.

\section{Materials and Methods}

The comprehensive assessment tool, implemented in the framework of the PHUSICOS project [12], consists of the estimation of a set of KPIs for evaluating the performance of project scenarios (NBS, HS, or GS), defined to opportunely take into account the key co-benefits and ecosystem services. Once the KPIs are quantified for the different project scenarios, by using a multi-level aggregation and weighting procedure, an overall score is evaluated. The final scenario score represents a measurement of the overall performance of the scenario and can be used for comparing different alternatives.

For the construction of the indicator matrix, the selection of proper KPIs is required. Considering the PHUSICOS project that focuses on rural mountain areas, hazards, and related co-benefits, project scenarios (PS) performance were evaluated using pools of criteria label "ambits". They were identified using a top-down procedure which started with the definition of five main ambits: (1) risk reduction, (2) technical and feasibility aspects; (3) environment and ecosystems; (4) society; (5) local economy. For each ambit, a number of several criteria are considered (14 according to the current configuration), as summarized in Table 1. 
Table 1. Ambits and criteria composing the assessment framework tool.

\begin{tabular}{|c|c|c|c|c|c|}
\hline Ambit & $\begin{array}{c}\text { Risk } \\
\text { Reduction }\end{array}$ & $\begin{array}{l}\text { Technical and } \\
\text { Feasibility } \\
\text { Aspects }\end{array}$ & $\begin{array}{l}\text { Environment and } \\
\text { Ecosystems }\end{array}$ & Society & Local Economy \\
\hline Criteria & $\begin{array}{l}\text { 1. Hazard } \\
\text { 2. Exposure } \\
\text { 3. Vulnerability }\end{array}$ & $\begin{array}{l}\text { 4. Technical } \\
\text { feasibility }\end{array}$ & $\begin{array}{l}\text { 5. Water } \\
\text { 6. Soil } \\
\text { 7. Vegetation } \\
\text { 8. Landscape (green } \\
\text { infrastructure) } \\
\text { 9. Biodiversity }\end{array}$ & $\begin{array}{l}\text { 10. Quality of life } \\
\text { 11. Community } \\
\text { involvement and } \\
\text { governance } \\
\text { 12. Landscape } \\
\text { and heritage }\end{array}$ & $\begin{array}{l}\text { 13. Revitalization } \\
\text { of marginal areas } \\
\text { 14. Local economy } \\
\text { reinforcement }\end{array}$ \\
\hline
\end{tabular}

Finally, for each criterion a number of KPIs are defined, sorting the KPIs according to specific sub-criteria. The selected KPIs should be considered as an example of effective markers, deriving from an exhaustive literature and from on-field experience and expert-based support. The overall matrix contains 98 KPIs [12]. For each KPI additional properties are also specified, such as the unit of measurement (metric, Mt), the data type (typology, Tp), whether they should be maximized/minimized with respect to the BS (direction, $\rightleftarrows$ ), the data source for their estimation (source, S) and other information about their nature, time-scale, and compliance with the Sendai Framework Disaster Risk Reduction (SFDRR, [13]) and UN Sustainable Development Goals (UNSG, https://www.un.org/sustainabledevelopment/sustainable-development-goals/). For more details, please refer to [12].

Despite its well defined and hierarchic structure, the approach is highly flexible and can be easily customized by selecting indicators depending on the data availability and the level of detail required for the analysis. Specifically, the framework can be applied at two different stages:

- Ex-ante stage: during the design stage of the project, useful to compare different suitable scenarios. Different levels of accuracy can be taken into account;

- Ex-post stage: during the monitoring activities after the implementation, able to assess the effectiveness of the selected solution. A preliminary assessment factor approach can be detailed through the application of an extended matrix.

Thus, the assessment approach is based on the preliminary selection of significant KPIs and their estimation for both the BS and the considered PSs. Through a multi-level weighting and aggregation procedure, the total score of each PS is calculated, allowing the comparison between alternatives, representing a quantitative tool for decision-makers and managers.

In order to aggregate the KPIs, characterized by different metrics and typology, a normalization procedure is required. The normalization procedure allows the description of the indicators variation (with respect to the BS) with a score between 0 and 100. Indeed, specific formulations were derived for KPIs to be maximized or minimized [12] at the optimum. To take into account the susceptibility of the decision process to the stakeholder's background and expertise, a multi-level weighting procedure was then developed within the PHUSICOS project, allowing for estimation of the score $S_{j, i}$ of the normalized KPI $\bar{I}_{j, i}$ as:

$$
S_{j, i}=w_{I I I, a} \cdot w_{I I, l} \cdot w_{I, j} \cdot \bar{I}_{j, i}
$$

being $\sum_{j=1}^{m} w_{I, j}=1, \sum_{l=1}^{c} w_{I I, l}=1, \sum_{a=1}^{p} w_{I I I, a}=1$

where:

- $\quad w_{I, j}$, with $j=1, \ldots, m$, is the weight of the $j$-th normalized KPI $\bar{I}_{j, i}$ of the $m$ selected ones (first weighting level);

- $\quad w_{I I, l}$, with $l=1, \ldots, c$, is the weight of the $l$-th Criterion (of the $c$ selected) which includes the $j$-th KPI $\bar{I}_{j, i}$ (second weighting level);

- $\quad w_{I I I, a}$, with $a=1, \ldots, p$, is the weight of the $a$-th Ambit (of the $p$ selected) which include the $j$-th KPI $\bar{I}_{j, i}$ (third weighting level). 
The weight estimation can be performed by applying different techniques, such as the uniform weighting, the Likert ranking [14], or the pairwise comparison. The first two approaches resulted in being the most useful for the implemented application, resulting as easily manageable when many parameters have to be considered from a considerable number of stakeholders. Thus, within the frame of the PHUSICOS project, the uniform weighting is applied for the indicator weighting (First Level), whereas the Likert approach was considered for both the criterion and the ambit ones (second and third levels). Specifically, the Likert scale from 1 ("not at all important") to 5 ("very important") was taken into account.

The multi-level weighting procedure allows for the estimation of not only the score of the overall PS but also the score of single KPI and criterion, as well. Thus, the proposed framework can be intended as an effective tool when stakeholders having different preferences and expertise, are involved through Living Lab (LL) techniques. Indeed, it provides a quantitative estimation of the PS performances, getting results that can be effectively used to support the decision-making process.

\section{The Isar River (DE) Restoration}

The Isar River (DE) is one of the main tributaries of the Danube, sourcing in the Alps and crossing the metropole of Munich. Since the 19th century, severe flooding events took place, provoking significant damages from the environment and socio-economic viewpoints. To limit the flood risk, a comprehensive flood plan was activated, aimed at canalizing the riverbed and performing an effective hydraulic regulation. As a consequence of the increasing river incision deriving from grey infrastructures and unsolved flood risk, the state of Bavaria, in cooperation with local authorities and the involved stakeholders, approved the design of several NBSs (implementation starting in 1999), able to improve both the ecological status of the river and the recreational attractiveness of the surrounding areas [15]. The Isar-Plan (2000 to 2011) is one of the most important measures implemented. The Isar river is thus intended within the PHUSICOS project as an example of the successful implementation of a flood risk management plan and related river restoration, providing effective knowledge about the LL application and stakeholder involvement. Through "look-and-learn" visits, the experiences are shared with other PHUSICOS partners, promoting the good practices acquired within the river restoration project implementation.

The main risk to the urban areas considered in the Isar River (DE) concept case is thus the propagation of flash floods caused by intense summer rainfall events in the Alps and snow melting [16]. The Bavarian Water Agency recorded flow rates of the river in Munich varying from 8 to $1.050 \mathrm{~m}^{3} / \mathrm{s}$ (http://www.hnd.bayern.de), forecasting a further increase of about $25 \%$ due to CC [17]. The implemented NBSs, as depicted in Figure 1, were mainly devoted to: (a) increasing the water retention capacity; (b) improving the natural riverine morphological processes; (c) settling the longitudinal continuity and replacing the steep embankments. Moreover, further assessment of the ecological improvements, such as the fish species refuge during flood events [17] and forest restoration are under development.

The Isar risk management plan required a budget of about $35 \mathrm{M€}$, founded by the Bavarian State Government (55\%) and the City of Munich Municipality (45\%). The planning process was launched in 1987 by the State Office of Water Management, Munich, and the City of Munich [15]. The restoration works began in February 2000 and finished in 2013. During the different stages of the process, a peculiar aspect of the Isar restoration was the continuous participative process. Indeed, the selection of measures to be undertaken was done with the effective involvement of many stakeholders, such as governmental offices and the "Isar-Allianz", a group of Non-Governmental Organizations (NGOs) representing end-users. 

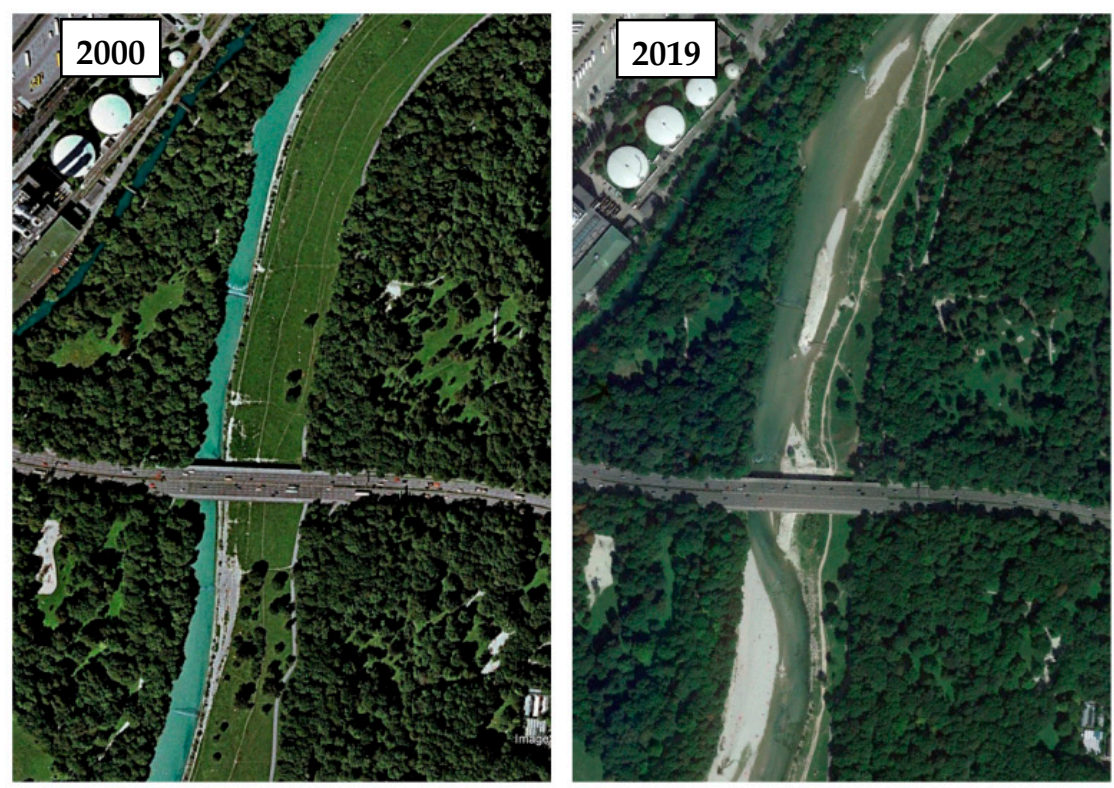

Figure 1. Satellite view of the urban reach of the Isar River (DE) before and after the river restoration implementation (photos from Google Earth).

\section{Application of the Framework Tool for NBSs Assessment to the Isar River (DE) Concept Case}

The framework assessment tool, implemented within the PHUSICOS project, was preliminarily applied to the Isar River (DE), with reference to a simplified matrix of 28 KPIs. The selected indicators covered all the five ambits of the framework, belonging to 10 criteria and 15 sub-criteria. The analysis was carried out comparing the implemented NBS Scenario with a virtual Grey Scenario, in which the flood-risk management would have been performed by designing a $1.5 \mathrm{~m}$-high dyke elevation and vegetation removal at the existing dykes to enable low-cost rehabilitation measures. The performance of the two PSs was then estimated in comparison with the BS. Through the LL approach, different groups of Stakeholders were invited to weight both the ambits and the criteria, using the Likert scale and providing a score from one to five. A uniform weighting was set for the KPIs, instead. The stakeholders belonged to different categories: NGOs, public (PuOs), and private (PrOs) organizations. The average weights of ambits and criteria for each stakeholder category are summarized in Tables 2 and 3, respectively.

Table 2. Results of the ambits weighting procedure for the Isar River (DE) concept case.

\begin{tabular}{cccc}
\hline Ambit & $\begin{array}{c}\text { Non-Governmental } \\
\text { Organizations (NGOs) }\end{array}$ & $\begin{array}{c}\text { Public } \\
\text { Organizations } \\
\text { (PuOs) }\end{array}$ & $\begin{array}{c}\text { Private } \\
\text { Organizations } \\
\text { (PrOs) }\end{array}$ \\
\hline Risk Reduction & 4.3 & 4.2 & 4.0 \\
\hline $\begin{array}{c}\text { Technical and } \\
\text { Feasibility Aspects }\end{array}$ & 4.2 & 3.9 & 4.3 \\
\hline $\begin{array}{c}\text { Environment and } \\
\text { Ecosystems }\end{array}$ & 4.5 & 4.4 & 5.0 \\
\hline Society & 4.7 & 4.4 & 5.0 \\
\hline Local Economy & 2.0 & 2.2 & 2.7 \\
\hline
\end{tabular}


Table 3. Results of Criteria weighting procedure for the Isar River (DE) concept case.

\begin{tabular}{cccc}
\hline Ambit & $\begin{array}{c}\text { Non-Governmental } \\
\text { Organizations (NGOs) }\end{array}$ & $\begin{array}{c}\text { Public } \\
\text { Organizations } \\
\text { (PuOs) }\end{array}$ & $\begin{array}{c}\text { Private } \\
\text { Organizations } \\
\text { (PrOs) }\end{array}$ \\
\hline Hazard & 3.5 & 4.0 & 4.0 \\
\hline Technical Feasibility & 4.0 & 3.0 & 4.0 \\
\hline Water & 3.7 & 4.2 & 4.3 \\
\hline Soil & 3.7 & 4.2 & 4.3 \\
\hline Vegetation & 3.7 & 4.1 & 4.0 \\
\hline Biodiversity & 3.8 & 4.5 & 5.3 \\
\hline Quality of Life & 4.5 & 4.4 & 4.0 \\
\hline $\begin{array}{c}\text { Community } \\
\text { Involvement and } \\
\text { Governance }\end{array}$ & 4.2 & 3.7 & 3.7 \\
\hline $\begin{array}{c}\text { Landscape and } \\
\text { Heritage }\end{array}$ & 2.7 & 2.8 & 2.0 \\
\hline $\begin{array}{c}\text { Revitalization of } \\
\text { Marginal Areas }\end{array}$ & 1.2 & 1.6 & \\
\hline
\end{tabular}

For the sake of brevity, only the scoring aggregation for ambits is reported in Table 4, with reference to the NBS and GS for each stakeholder category.

Table 4. Ambit scoring for the Isar River (DE) concept case.

\begin{tabular}{ccccccc}
\hline \multirow{2}{*}{ AMBIT } & \multicolumn{2}{c}{$\begin{array}{c}\text { Non-Governmental } \\
\text { Organizations } \\
\text { (NGOs) }\end{array}$} & \multicolumn{2}{c}{$\begin{array}{c}\text { Public Organizations } \\
\text { (PuOs) }\end{array}$} & \multicolumn{2}{c}{$\begin{array}{c}\text { Private Organizations } \\
\text { (PrOs) }\end{array}$} \\
\cline { 2 - 7 } & Grey Sc. & NBS Sc. & Grey Sc. & NBS Sc. & Grey Sc. & NBS Sc. \\
\hline $\begin{array}{c}\text { Risk } \\
\text { Reduction }\end{array}$ & 0.000005 & 0.000005 & 0.000005 & 0.000005 & 0.000004 & 0.000004 \\
\hline $\begin{array}{c}\text { Technical and } \\
\text { Feasibility } \\
\text { Aspects }\end{array}$ & 0.060764 & 0.010851 & 0.041811 & 0.007466 & 0.052021 & 0.009289 \\
\hline $\begin{array}{c}\text { Environment } \\
\text { and }\end{array}$ & -0.064453 & 0.372037 & -0.071471 & 0.413924 & -0.069671 & 0.383130 \\
Ecosystems & -0.007292 & 0.882265 & -0.006589 & 0.804494 & -0.007146 & 0.905822 \\
\hline Society & 0.012500 & 0.025000 & 0.017970 & 0.035940 & 0.022866 & 0.045733 \\
\hline $\begin{array}{c}\text { Local } \\
\text { Economy }\end{array}$ & $\mathbf{0 . 0 0 1 5 2 4}$ & $\mathbf{1 . 2 9 0 1 5 8}$ & $-\mathbf{0 . 0 1 8 2 7 4}$ & $\mathbf{1 . 2 6 1 8 3 0}$ & $-\mathbf{0 . 0 0 1 9 2 5}$ & $\mathbf{1 . 3 4 3 9 7 8}$ \\
\hline $\begin{array}{c}\text { TOTAL } \\
\text { SCORE }\end{array}$ & & & & & & \\
\hline
\end{tabular}

\section{Discussion}

The NBS scenario achieved the highest score, independently from the considered stakeholders. Indeed, the two compared PSs presented similar performances in terms of risk reduction with the NBS presenting, on one hand, higher investment and management costs and, on the other hand, greater improvements from both the environment and the socio-economic viewpoints. The low score of risk reduction ambit, being significantly lower than those of other ambits was mainly due to the selection of a single PKI, namely the flooding volume of the riverbed resulting slightly lower than that observed at the BS, for both the NBS and GS. Negative scores, observed for the GS, were mainly derived from the predicted increase in temperature (environment and ecosystems ambit) and the reduction of recreational areas (society ambit), instead. In greater detail, for the NBS scenario higher 
scores for environment and ecosystem were observed when considering the NGOs and PrOs weights. The society ambit reached higher scores with the PuOs and PrOs weights, instead. Concerning the GS, NGOs weights resulted in higher scores for technical aspects, whereas PrOs weights provided higher scores for the local economy ambit.

In Figure 2 the scorings of different stakeholders are compared for NBS and Grey scenarios in terms of ambits scoring (Figure 2a,b) and criteria scoring (Figure 2c,d).

Similar results were observed when considering the criteria scoring. The different stakeholders defined analogous weights and, thus, negligible discrepancies were obtained from the different weighting schemes.

Finally, the ambits and criteria scoring were plotted for the NBS scenario versus the GS, evaluated adopting weights obtained by averaging the weights corresponding to each stakeholder. In terms of ambit scoring, the NBS and GS gave analogous results for risk reduction, technical and feasibility aspects, and local economy ambits. The NBS scenario was found to be highly preferable when considering the social and environmental co-benefits, instead.

Specifically, at the criteria scoring, the social aspects made the NBS scenario significantly preferable, as a consequence of the improved quality of life, and the creation of a scenic site and new landscape units. Notably, environmental aspects also made the NBS solution favorable and, specifically, the vegetation and biodiversity connected co-benefits.

Conversely, with analogous risk reduction performance, the GS resulted in being preferable from the technical and feasibility viewpoints.

However, in any case, examining the scenario scoring, the NBS was highly preferable, as plotted in Figure 3.

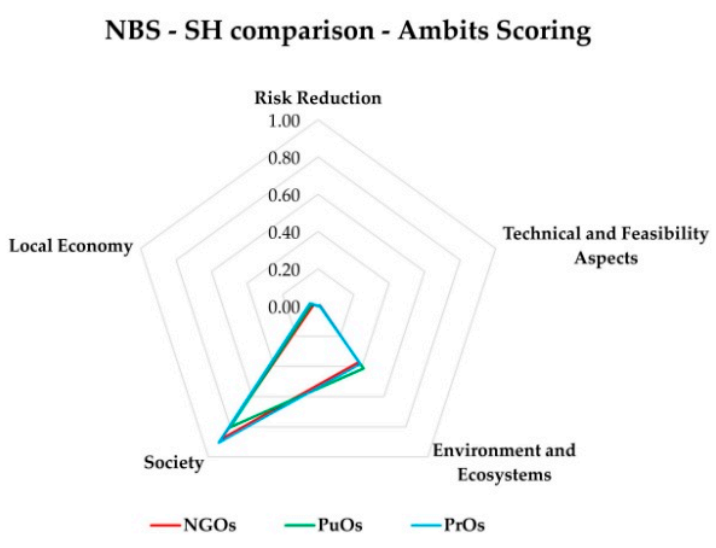

(a)

NBS - SH comparison - Criteria Scoring

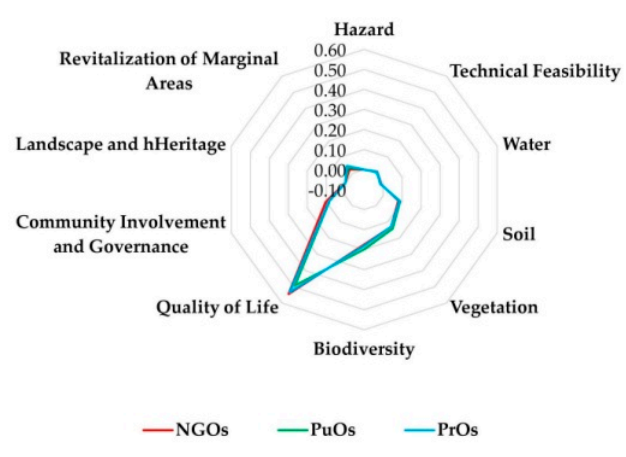

(c)

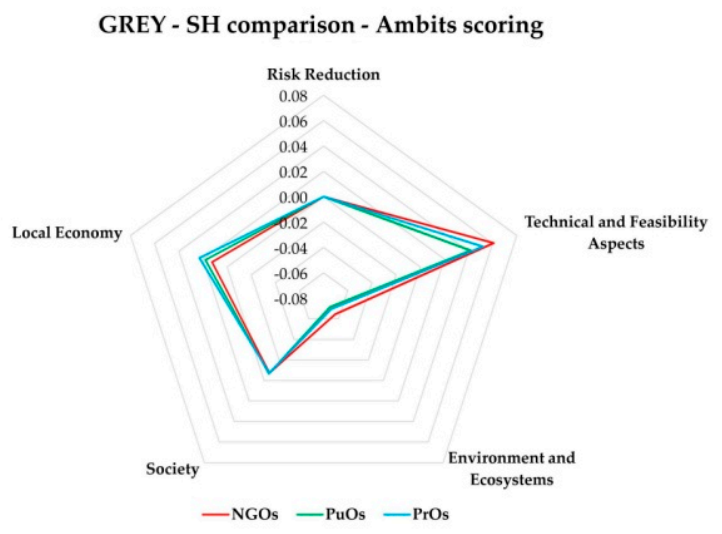

(b)

Grey - SH comparison - Criteria Scoring

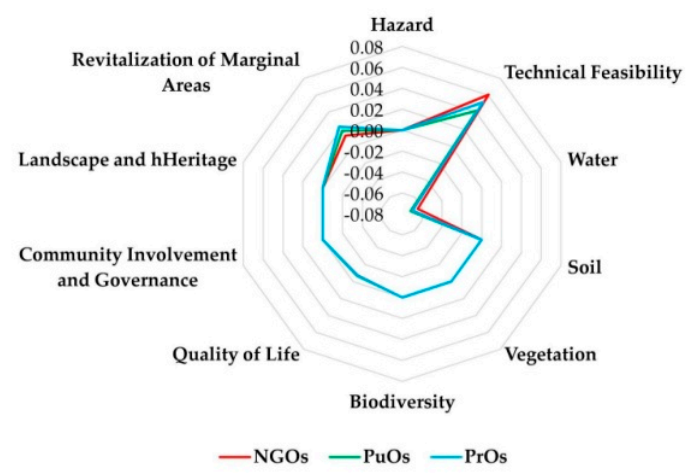

(d)

Figure 2. (a) Ambits scoring for the NBS scenario; (b) ambits scoring for the grey scenario; (c) criteria scoring for the NBS scenario; (d) criteria scoring for the grey scenario. 


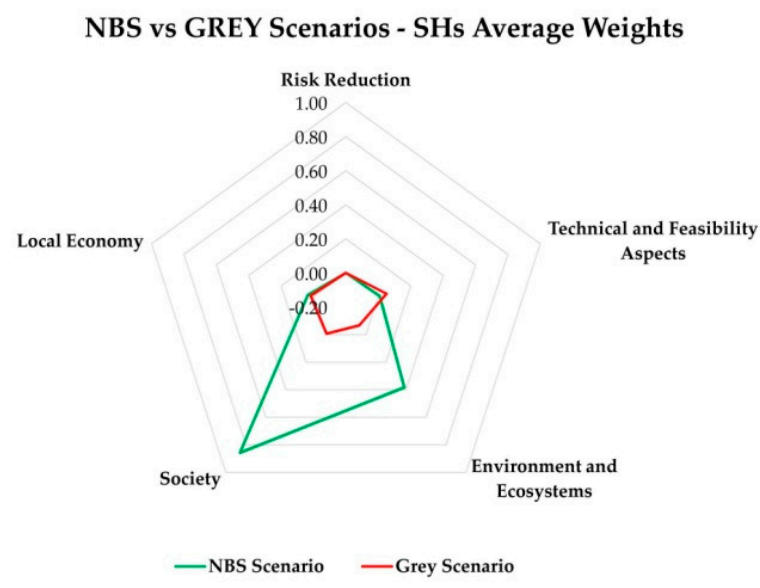

(a)
NBS vs GREY Scenarios - SHs Average Weights

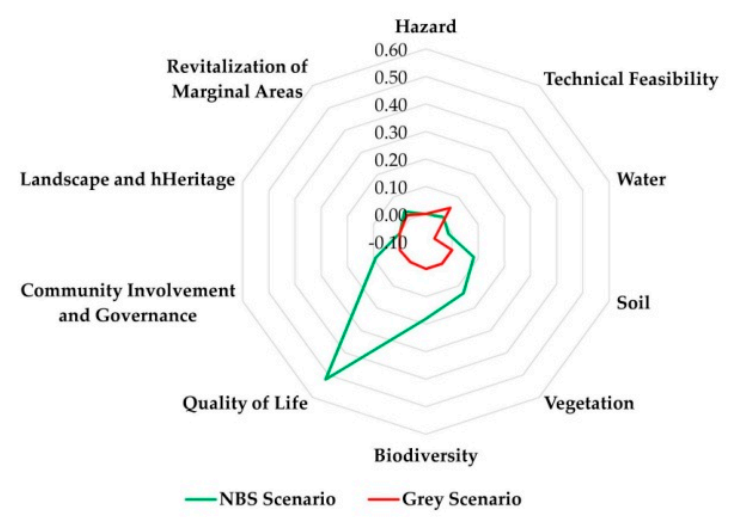

(b)

Figure 3. (a) Ambits scoring for stakeholders average weights; (b) criteria scoring for stakeholders average weights.

\section{Conclusions}

In this work, the preliminary results deriving from the application to the Isar River (DE) concept case of the comprehensive framework tool for NBSs assessment, developed in the frame of the PHUSICOS project, are provided and discussed. The matrix was tailored in consideration of the available preliminary data and the site-specific hazards. Specifically, the opinions of three different stakeholder categories were investigated and integrated into the weighting procedure, as a result of the direct involvement of stakeholders through a living lab procedure, comparing two project scenarios: an NBS and grey solution.

Comparable results were observed with the different stakeholder groups, resulting in the NBS scenario being the most advisable solution. Specifically, the highest scores were attained for the environmental and societal ambits, whereas the risk reduction, and technical and local economy ambit reached comparable results.

The NBS selection was mainly sustained by the higher relevance provided to the quality of life, environment and ecosystem, landscape, and heritage improvement criteria.

The ongoing activities are focused on the integration of achieved results with the estimation of further KPIs, with the aim of making the assessment more consistent.

Author Contributions: All authors have read and agreed to the published version of the manuscript. Conceptualization, F.P., G.C. and M.G.; methodology, G.C., A.Z.-H. and G.L.; validation, F.P. and G.C.; formal analysis, G.C. and M.G.; resources, A.Z.-H. and G.L.; data curation, A.Z.-H. and G.L.; writing-original draft preparation, F.P.; writing - review and editing, G.C., A.Z.-H. and G.L.; supervision M.G.; project administration, M.G. All authors have read and agreed to the published version of the manuscript.

Funding: This research was funded by the H2020 Innovation Action "PHUSICOS-According to Nature" (Grant Agreement No. 776681).

Acknowledgments: The authors would like to thank G. Urciuoli, M. Stanganelli, F. De Paola, Silvia Autuori, and Carlo Gerundo of the University of Naples Federico II, Stephan Pauleit of the Technical University of Munich and all the partners of the PHUSICOS consortium for their support in the developed activities. The authors would like to express sincere appreciation to all who contributed time, experience, and knowledge to support the development of this contribution. The authors especially like to thank the local stakeholders that invest time in participating in the weighting procedure.

Conflicts of Interest: The authors declare no conflict of interest. 


\section{References}

1. Beniston, M. Linking extreme climate events and economic impacts: Examples from the Swiss Alps. Energy Policy 2007, 35, 5384-5392, doi:10.1016/j.enpol.2006.01.032.

2. De Paola, F.; Giugni, M.; Pugliese, F.; Romano, P. Optimal Design of LIDs in Urban Stormwater Systems Using a Harmony-Search Decision Support System. Water Resour. Manag. 2018, 32, 4933-4951. doi:10.1007/s11269-018-2064-8.

3. Shafique, M.; Kim, R. Low impact development practices: A review of current research and recommendations for future directions. Ecol. Chem. Eng. S 2015, 22, 543-563.

4. European Commission, E.U. Towards an EU Research and Innovation Policy Agenda for Nature-Based Solutions $\mathcal{E}$ Re-Naturing Cities; Pubblication Office of the European Union: Luxembourg, 2020; ISBN 9789279460517.

5. Zingraff-Hamed, A.; Greulich, S.; Wantzen, K.M.; Pauleit, S. Societal drivers of european water governance: A comparison of Urban river restoration practices in france and Germany. Water (Switzerland) 2017, 9, 206. doi:10.3390/w9030206.

6. Albert, C.; Spangenberg, J.H.; Schröter, B. Nature-based solutions: Criteria. Nature 2017, 543, 315.

7. Maes, J.; Jacobs, S. Nature-Based Solutions for Europe's Sustainable Development. Conver Lett. 2015, 1-4, doi:10.1111/conl.12216.

8. Korup, O.; Clague, J.J. Natural hazards, extreme events, and mountain topography. Quat. Sci. Rev. 2009, 28, 977-990. doi:10.1016/j.quascirev.2009.02.021.

9. Huang, I.B.; Keisler, J.; Linkov, I. Multi-criteria decision analysis in environmental sciences: Ten years of applications and trends. Sci. Total Environ. 2011, 409, 3578-3594.

10. Cinelli, M.; Coles, S.R.; Kirwan, K. Analysis of the potentials of multi criteria decision analysis methods to conduct sustainability assessment. Ecol. Indic. 2014, 46, 138-148.

11. Belton, V.; Stewart, T. Multiple Criteria Decision Analysis: An Integrated Approach; Springer Nature Book Archives Millennium; Springer: New York, NY, USA, 2002; ISBN 9780792375050.

12. Autuori, S.; Caroppi, G.; De Paola, F.; Giugni, M.; Pugliese, F.; Stanganelli, M.; Urciuoli, G. Comprehensive Framework for NBS Assessment. Deliverable D4.1 of the H2020 Innovation Action "PHUSICOSAccording to Nature" Project (Grant Agreement No. 776681), 2019. Available online: https://phusicos.eu/wpcontent/uploads/2019/05/D4.1_Task4.1_UNINA_14052019_Final_withAppendicies.pdf (accessed on 18 August 2020).

13. Aitsi-Selmi, A.; Egawa, S.; Sasaki, H.; Wannous, C.; Murray, V. The Sendai Framework for Disaster Risk Reduction: Renewing the Global Commitment to People's Resilience, Health, and Well-being. Int. J. Disaster Risk Sci. 2015, 6, 164-176. doi:10.1007/s13753-015-0050-9.

14. Cohen, L.; Manion, L.; Morrison, K. Res. Methods in Education; Taylor and Francis Group: London, UK, 2017.

15. Aude, Z.-H.; Juliette, M.; Gerd, L.; Joanne, L.-B.; Stephan, P. Designing a resilient waterscape using a living lab and catalyzing polycentric governance. Landsc. Archit. Front. 2019, 7, 12-31. doi:10.15302/j-laf-1-020003.

16. Zingraff-Hamed, A.; Egger, G. Isar. In Rivers of the Alps-Diversity in Nature and Culture; Haupt Verlag AG: Bern, Switzerland, 2019; pp. 408-412, ISBN 9783258081175.

17. Zingraff-Hamed, A.; Noack, M.; Greulich, S.; Schwarzwälder, K.; Wantzen, K.M.; Pauleit, S. Model-based evaluation of urban river restoration: Conflicts between sensitive fish species and recreational users. Sustainability 2018, 10, 1747. doi:10.3390/su10061747. 